Article

\title{
Clinical and Functional Characterization of the Recurrent TUBA1A p.(Arg2His) Mutation
}

\author{
Jennifer F. Gardner ${ }^{1,+}$, Thomas D. Cushion ${ }^{2,+}$ (D), Georgios Niotakis ${ }^{3}$, Heather E. Olson ${ }^{4}$, \\ P. Ellen Grant ${ }^{5}$, Richard H. Scott ${ }^{6}$, Neil Stoodley ${ }^{7}$, Julie S. Cohen ${ }^{8}$, Sakkubai Naidu ${ }^{8,9,10}$, \\ Tania Attie-Bitach 11,12, Maryse Bonnières ${ }^{11}$, Lucile Boutaud 11,12, Férechté Encha-Razavi ${ }^{11}$, \\ Sheila M. Palmer-Smith ${ }^{1}$, Hood Mugalaasi ${ }^{1}$, Jonathan G. L. Mullins ${ }^{13}$, Daniela T. Pilz ${ }^{2,14}$ and \\ Andrew E. Fry 1,2,* (iD)
}

1 Institute of Medical Genetics, University Hospital of Wales, Cardiff CF14 4XW, UK; jennifer.gardner@wales.nhs.uk (J.F.G.); sheila.palmer-smith@wales.nhs.uk (S.M.P.-S.); hood.mugalaasi@wales.nhs.uk (H.M.)

2 Division of Cancer and Genetics, School of Medicine, Cardiff University, Cardiff CF14 4XN, UK; cushiont@cardiff.ac.uk (T.D.C.); pilzdt@cardiff.ac.uk (D.T.P.)

3 Paediatrics Department, Venizelion Hospital, Knossos Ave, P.O. Box 44, Heraklion, 71409 Crete, Greece; niotakisg@yahoo.gr

4 Epilepsy Genetics Program, Department of Neurology, Division of Epilepsy and Clinical Neurophysiology, Boston Children's Hospital, Boston, MA 02115, USA; heather.olson@childrens.harvard.edu

5 Fetal-Neonatal Neuroimaging and Developmental Science Center, Boston Children's Hospital, Harvard Medical School, Boston, MA 02115, USA; ellen.grant@childrens.harvard.edu

6 Clinical Genetics Unit, Great Ormond Street Hospital for Children NHS Trust, Great Ormond Street, London WC1N 3JH, UK; richard.scott@genomicsengland.co.uk

7 Department of Neuroradiology, North Bristol NHS Trust, Frenchay Hospital, Bristol BS16 1LE, UK; neilstoodley@doctors.org.uk

8 Division of Neurogenetics, Hugo W. Moser Research Institute, Kennedy Krieger Institute, Baltimore, MD 21205, USA; cohenju@kennedykrieger.org (J.S.C.); naidu@kennedykrieger.org (S.N.)

9 Department of Neurology, The Johns Hopkins Hospital, Baltimore, Maryland, MD 21287, USA

10 Department of Pediatrics, The Johns Hopkins Hospital, Baltimore, Maryland, MD 21287, USA

11 Unité d'Embryofœtopathologie, Service d'Histologie Embryologie Cytogénétique, Hôpital Necker-Enfants Malades, Assistance Publique Hôpitaux de Paris (APHP), 75004 Paris, France; tania.attie@inserm.fr (T.A.-B.); maryse.bonniere-darcy@aphp.fr (M.B.); lucile.boutaud@gmail.com (L.B.); ferechte.razavi@aphp.fr (F.E.-R.)

12 Institut Imagine, INSERM U1163, Université Paris Descartes, Sorbonne Paris Cite, 75006 Paris, France

13 Institute of Life Science, Swansea University Medical School, Swansea SA2 8PP, UK; j.g.l.mullins@swansea.ac.uk

14 Department of Clinical Genetics, West of Scotland Regional Genetics Service, Queen Elizabeth University Hospital, Glasgow G51 4TF, UK

* Correspondence: fryae@cardiff.ac.uk; Tel.: +44-292-074-3151

+ These authors contributed equally to this work.

Received: 30 May 2018; Accepted: 17 July 2018; Published: 7 August 2018

Abstract: The TUBA1A gene encodes tubulin alpha-1A, a protein that is highly expressed in the fetal brain. Alpha- and beta-tubulin subunits form dimers, which then co-assemble into microtubule polymers: dynamic, scaffold-like structures that perform key functions during neurogenesis, neuronal migration, and cortical organisation. Mutations in TUBA1A have been reported to cause a range of brain malformations. We describe four unrelated patients with the same de novo missense mutation in TUBA1A, c.5G>A, p.(Arg2His), as found by next generation sequencing. Detailed comparison revealed similar brain phenotypes with mild variability. Shared features included developmental delay, microcephaly, hypoplasia of the cerebellar vermis, dysplasia or thinning of the corpus callosum, small pons, and dysmorphic basal ganglia. Two of the patients had bilateral perisylvian polymicrogyria. We examined the effects of the p.(Arg2His) mutation 
by computer-based protein structure modelling and heterologous expression in HEK-293 cells. The results suggest the mutation subtly impairs microtubule function, potentially by affecting inter-dimer interaction. Based on its sequence context, c.5G $>\mathrm{A}$ is likely to be a common recurrent mutation. We propose that the subtle functional effects of p.(Arg2His) may allow for other factors (such as genetic background or environmental conditions) to influence phenotypic outcome, thus explaining the mild variability in clinical manifestations.

Keywords: TUBA1A; tubulin; p.(Arg2His), R2H; tubulinopathy; polymicrogyria; cerebellar hypoplasia

\section{Introduction}

TUBA1A is a highly-conserved gene with few changes among eukaryotes and few polymorphic variants in human populations. TUBA1A encodes the tubulin alpha-1A chain, a protein that is highly-expressed in the cerebral cortex, hippocampus, cerebellum, and brainstem of the developing fetal brain, with a decrease in postnatal and adult stages [1,2]. Alpha- and beta-tubulin subunits form dimers that coassemble into microtubules. Microtubules are dynamic polymers that perform a range of mechanical tasks within the cell. As major components of the mitotic spindle, microtubules control division of neuronal progenitors to produce neurons. In turn, they generate the push-and-pull forces that are required for the migration of primitive neurons, from deep proliferative areas to the cortical plate. Subsequently, bundles of stable and polarised microtubule polymers generate long axons facilitating cortical organisation and synaptic connectivity.

TUBA1A was the first tubulin gene to be associated with human brain malformations [3]. Mutations in TUBA1A have been reported in patients with a range of brain malformations, including lissencephaly, microlissencephaly, polymicrogyria, and simplified gyri [4-6]. They have also been reported in patients with hydranencephaly-like dysplasias, cerebral palsy, and autistic spectrum disorders [7-9]. TUBA1A mutations (as with other tubulinopathies) are often associated with hypoplasia/agenesis of the corpus callosum, hypoplasia/dysplasia of the cerebellum, and dysmorphic basal ganglia [5,6]. Common clinical features in TUBA1A patients include microcephaly, intellectual disability, motor impairment, and epilepsy. Mutations in several other tubulin genes have been reported in patients with brain malformations including TUBB2B [10], TUBB3 [11,12], TUBB [13], TUBB2A [14], and TUBG1 [15]. However, TUBA1A mutations remain the most common cause of tubulin-related brain malformations, with over 60 mutations being described to date [6]. Most disease-causing TUBA1A mutations are de novo, although familial recurrence due to parental somatic mosaicism has been reported [4,16].

Pathogenic TUBA1A mutations have been found distributed throughout the gene. A handful of recurrent TUBA1A mutations have been reported. These include the p.(Arg402His) mutation, which has been reported in at least five patients and is associated with classic lissencephaly $[3,17]$. Similarly, the recurrent p.(Arg264Cys) mutation has been found in several patients and is typically associated with central pachygyria $[3,18,19]$. Few genotype-phenotype correlations have been reported for TUBA1A. However, the phenotypic effects of a specific recurrent mutation are generally consistent. Alpha-tubulin must fold in a precise way and present specific shapes and charges on its surface to interact with other proteins (e.g., beta-tubulin subunits, microtubule binding proteins) and to correctly handle and hydrolyse guanosine- $5^{\prime}$-triphosphate (GTP). Many TUBA1A mutations have been shown to disrupt protein folding and/or heterodimer formation, resulting in either a reduced yield or reduced stability [20].

During the clinical diagnostic work-up of two unrelated patients with developmental delay and brain abnormalities, we identified the same mutation, c.5G>A, p.(Arg2His), in TUBA1A. To define the clinical consequences of this mutation, we collected detailed phenotype information from both patients and two additional patients that were previously reported in the literature [21-23]. We examined 
the functional impact of the mutation by in vitro microtubule studies and computer-based protein structure modeling.

\section{Materials and Methods}

\subsection{Patients}

Patients 1 and 2 were diagnosed during routine clinical diagnostic work-ups. Patient 1 underwent testing with a 12-gene polymicrogyria sequencing panel (targets enriched by Agilent SureSelect system, followed by Illumina sequencing) in the United States. Patient 2 had testing with a 40 gene cortical malformation gene panel (HaploPlex target enrichment system followed by Illumina sequencing) in the United Kingdom. The mutations in Patients 1 and 2 were confirmed and shown to be de novo by Sanger sequencing in the patient and both parents. Patient 3 underwent trio-based whole exome sequencing (WES) as a part of their routine clinical diagnostic work-up in the United States $[21,23]$. The approach to analysis and filtering of the WES data has previously been described [21]. No other candidate variants were identified in the patient. Patient 4 underwent targeted sequencing of a panel of 423 genes that are associated with corpus callosum anomalies in France [22]. The approach to analysis and filtering of this panel has previously been described [24,25]. No other candidate variants were identified in the patient. Consent was obtained from the parents of all the participants for publication. The genomic location of the mutation is chr12:g.49580615C $>\mathrm{T}$ (GRCh37/hg19), rs587784491. Coding and protein positions of TUBA1A mutations are based on GenBank accession codes NM_006009.3 (ENST000000301071.7) and NP_006000.2, respectively.

\subsection{Homology Modelling}

Structural predictions of wild-type and mutant TUBA1A protein subunits were generated while using a previously-described homology modeling pipeline [26]. This approach uses the solved structure of a homologous template to predict the folding of a target sequence. The target sequence was wild-type TUBA1A (NP_006000.2). The template used was the crystal structure of Tubulin alpha-1B from Bos taurus (Protein Data Bank (PDB): 4I4T) [27], which shares 99\% sequencing identity with human TUBA1A. Microtubule architecture was based on a previously published template (PDB: 2XRP) [28]. Homology modelling was performed by MODELLER (version 9.17) [29]. Structural models were viewed and analysed while using the UCSF Chimera software (version 1.12) [30,31].

\subsection{Expression Construct Mutagenesis and Cell Culture}

A C-terminally FLAG-tagged wild-type TUBA1A expression construct (pRK5-TUBA1A-C-FLAG) was modified to generate TUBA1A-R2H by site-directed mutagenesis using the QuikChange mutagenesis kit (Stratagene, La Jolla, CA, USA). HEK-293 cells were cultured in Dulbecco's modified Eagle's media (ThermoFisher, Waltham, MA, USA, catalogue number 41966029), supplemented with $10 \%$ fetal calf serum (ThermoFisher, 10500056) and $1 \%$ penicillin/streptomycin (ThermoFisher, 15070063), as previously described [14].

\subsection{Immunocytochemistry}

HEK-293 cells were cultured in Dulbecco's modified Eagle's media (ThermoFisher, 41966029). supplemented with $10 \%$ fetal calf serum (ThermoFisher, 10500056) and $1 \%$ penicillin/streptomycin (ThermoFisher, 15070063) and incubated at $37{ }^{\circ} \mathrm{C} 5 \% \mathrm{CO}_{2}$. Cells were seeded onto poly-D-Lysine (Sigma-Aldrich, St. Louis, MO, USA, P6407) pre-coated $13 \mathrm{~mm}$ glass coverslips. After $24 \mathrm{~h}$, the cells were transfected with either wild-type or mutant expression constructs using Lipofectamine 2000 (ThermoFisher, 11668030). Twenty-four hours post-transfection, the cells were fixed with methanol at $-20{ }^{\circ} \mathrm{C}$ for five minutes. Fixed cells were blocked with blocking buffer (phosphate-buffered saline (PBS) with $2 \%$ Bovine Serum Albumin (BSA; Sigma-Aldrich, B4287) and 0.5\% Triton (Sigma-Aldrich, T8787)) for $30 \mathrm{~min}$ at room temperature $\left(23^{\circ} \mathrm{C}\right)$. Cells were immunostained with rabbit anti-FLAG 
(Sigma-Aldrich, F7425; 1:500) and mouse anti-alpha-tubulin (Sigma-Aldrich, T6199; 1:750) diluted in PBS with $2 \%$ BSA and $0.1 \%$ Triton for one hour at room temperature. Primary antibodies were aspirated, cells washed three times with PBS, and incubated with AlexaFluor ${ }^{568}$-conjugated goat anti-rabbit (ThermoFisher, A11011) and AlexaFluor ${ }^{488}$-conjugated goat anti-mouse (ThermoFisher, A11011) secondary antibodies for 30 minutes at room temperature, and protected from light from this point onwards. Cells were rinsed with PBS, mounted onto glass slides with ProLong Gold mounting medium (ThermoFisher, P10144) and stored at $4{ }^{\circ} \mathrm{C}$ until examined by confocal microscopy (Zeiss Axioscope).

\subsection{Predicting the Probability of TUBA1A Substitutions}

The genomic DNA sequence of the TUBA1A gene (based on transcript ENST00000301071.7) was obtained from the Ensembl Genome Browser [32]. A sliding window was implemented using a Perl script. For each 7-nucleotide window the script recorded the position and base of the central nucleotide. The heptanucleotide sequence was then looked up in the data from [33] (Supplementary Table 7 from that paper). The substitution probabilities for changing the central nucleotide to each of the three alternative bases were taken (averaging African, Asian, and European values). The cDNA and protein consequences of each substitution were derived using Mutalyzer [34,35]. Predicted substitution probabilities were obtained for all coding positions, introns ( \pm 20 base pairs flanking exons), and $5^{\prime}$ and 3 ' untranslated regions ( \pm 20 base pairs).

\section{Results}

\subsection{Clinical Features of Patients with the p.(Arg2His) Mutation}

We identified two unrelated patients (Patients 1 and 2) with the same TUBA1A missense mutation, c.5G>A, p.(Arg2His). A search of the literature found reports of two additional patients with the p.(Arg2His) mutation (Patients 3 and 4) [21-23]. Only brief descriptions of the two published subjects were previously available. We obtained detailed clinical information from the four individuals (Table 1 , detailed case reports are provided in the Supplementary Material). All four mutations were de novo. Consistent features in the living patients were developmental delay and microcephaly. MRI brain images from Patients 1-3 were available for review (Figure 1). The images demonstrated the hypoplasia and dysplasia of the cerebellar vermis (3/3), hypoplasia or dysgenesis of the corpus callosum (3/3), and dysmorphic basal ganglia (3/3). Patient 1 had bilateral perisylvian polymicrogyria. The pons of all three patients was small, particularly affecting the belly of the pons.

Patient 4 was a fetus terminated at 36 weeks gestation. Post-mortem examination of Patient 4 found a small brain (weight on 5th centile) with shortening of the corpus callosum and cerebellar hypoplasia (Figure 2A,B). Neuropathology examination found bilateral perisylvian polymicrogyria (Figure 2C-E). At the supratentorial level, callosal fibers and corticospinal tracts (CST) were hypoplastic. The brainstem was shortened and dysmorphic, displaying a Z-shaped kink. At the level of the cerebral peduncles, the CST were present but reduced in size. The pons was reduced in size in its basilar part. In the pons the CST were present at the junction with the peduncles but showed a chaotic pattern in between the pontine nuclei. The transverse pontine fibers were also reduced, and associated with cerebellar heterotopias and hypoplastic deep nuclei. At the level of the medulla, the pyramids were present but hypoplastic. The inferior olivary nuclei were also reduced in size. Neuronal heterotopia of the olivary nuclei was noted. At the cervical spinal cord level, crossing CST were absent. Cerebellar foliation was normal, but lamination was impaired with rare and misaligned Purkinje cells. 
Table 1. Clinical features of patients with the recurrent p.(Arg2His) TUBA1A mutation.

\begin{tabular}{|c|c|c|c|c|}
\hline Patient & 1 & 2 & 3 & 4 (fetus) \\
\hline Sex & Male & Male & Male & Male \\
\hline OFC at Birth & $30 \mathrm{~cm}(-3.6 \mathrm{SD})$ & $34 \mathrm{~cm}(-0.9 \mathrm{SD})$ & $33 \mathrm{~cm}(-1.7 \mathrm{SD})$ & $\mathrm{n} / \mathrm{a}$ \\
\hline Age at last review & 4 years & 32 months & 37 months & TOP at 36 weeks gestation \\
\hline Last OFC & $45 \mathrm{~cm}(-4.9 \mathrm{SD})$ & $43 \mathrm{~cm}(-5.9 \mathrm{SD})$ & $45 \mathrm{~cm}(-4.6 \mathrm{SD})$ & $\mathrm{n} / \mathrm{a}$ \\
\hline Developmental delay & Moderate & Severe & Moderate & $\mathrm{n} / \mathrm{a}$ \\
\hline Seizures & Yes (onset at 3 years) & Yes (onset at 12 months) & No & $\mathrm{n} / \mathrm{a}$ \\
\hline Cerebral cortex & $\begin{array}{l}\text { Bilateral perisylvian } \\
\text { polymicrogyria }\end{array}$ & Normal & Normal & $\begin{array}{l}\text { Bilateral perisylvian } \\
\text { polymicrogyria }\end{array}$ \\
\hline White matter & Reduced & Reduced & Reduced & $\mathrm{n} / \mathrm{k}$ \\
\hline Corpus callosum & Partial agenesis & Thin & Thin & Short, no rostrum \\
\hline Basal ganglia & Dysmorphic, prominent & Dysmorphic, prominent & $\begin{array}{l}\text { Dysmorphic, } \\
\text { prominent }\end{array}$ & $\mathrm{n} / \mathrm{k}$ \\
\hline Cerebellum & $\begin{array}{c}\text { Hypoplasia and } \\
\text { dysplasia of vermis }\end{array}$ & $\begin{array}{c}\text { Hypoplasia and } \\
\text { dysplasia of vermis }\end{array}$ & $\begin{array}{c}\text { Hypoplasia and } \\
\text { dysplasia of } \\
\text { vermis }\end{array}$ & $\begin{array}{l}\text { Hypoplasia, Impaired } \\
\text { lamination, rare and } \\
\text { misaligned Purkinje }\end{array}$ \\
\hline Brainstem & Small pons & Small pons & Small pons & $\begin{array}{l}\text { Neuronal heterotopia of } \\
\text { olivary nuclei and } \\
\text { hypoplastic pyramids }\end{array}$ \\
\hline
\end{tabular}

Key: $n / a / k=$ not applicable $/$ known; OFC = occipital frontal circumference; PMG = polymicrogyria; $\mathrm{SD}$ = standard deviations; TOP = termination of pregnancy.

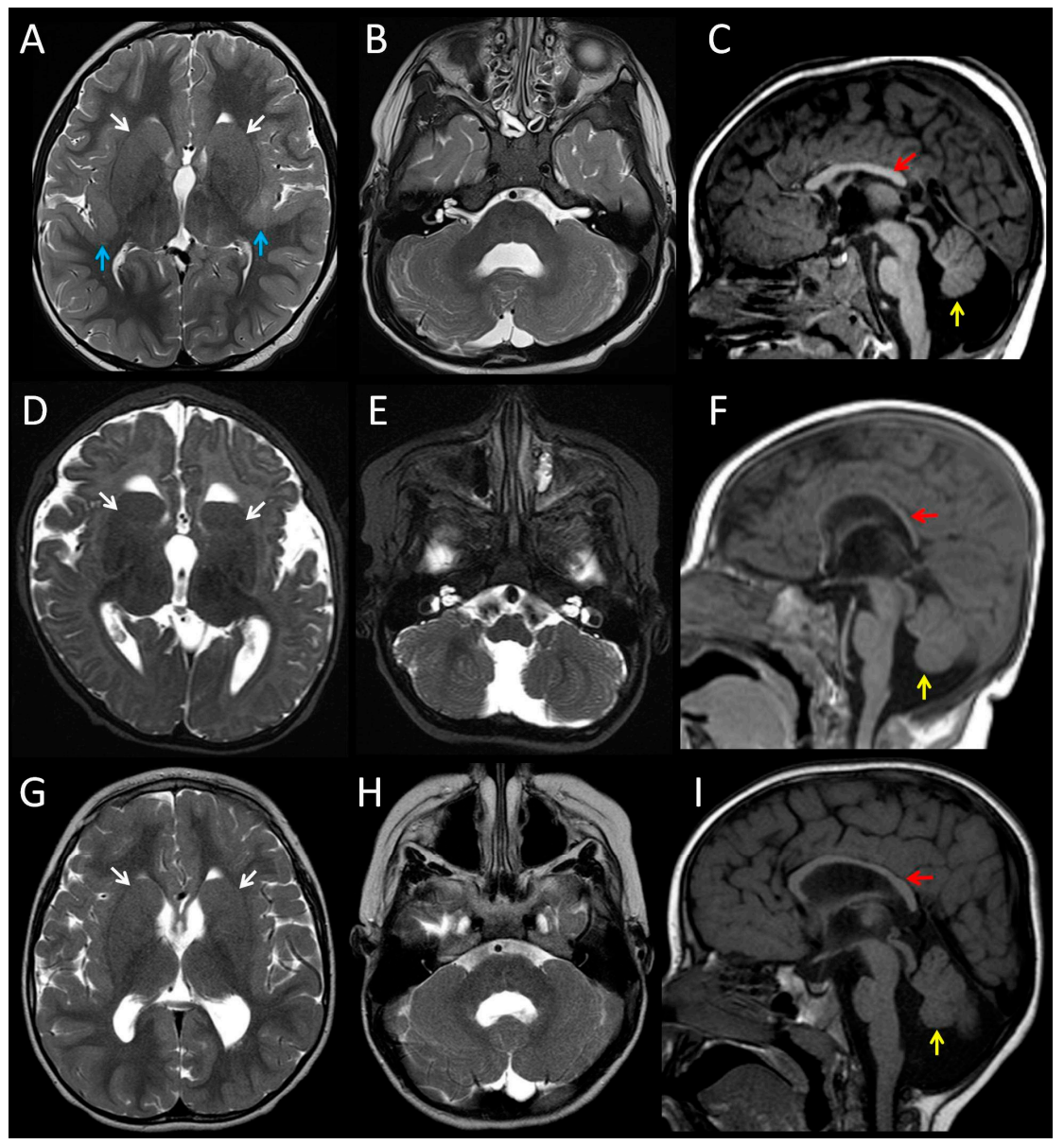

Figure 1. Magnetic resonance images from patients with the recurrent p.(Arg2His) TUBA1A mutation. T2-weighted axial and T1-weighted midline sagittal brain images for Patient 1 at age three years (A-C), Patient 2 at age six months (D-F), and Patient 3 at age 19 months (G-I). The images demonstrate hypoplasia and dysplasia of the cerebellar vermis (yellow arrows), thinning or partial agenesis of the corpus callosum (red arrows), globular basal ganglia with incomplete formation of the anterior limb internal capsule (white arrows), and bilateral perisylvian polymicrogyria (blue arrows). The pons is similar in size to the midbrain which suggests the pons is relatively small $(\mathbf{C}, \mathbf{F}, \mathbf{I})$. 

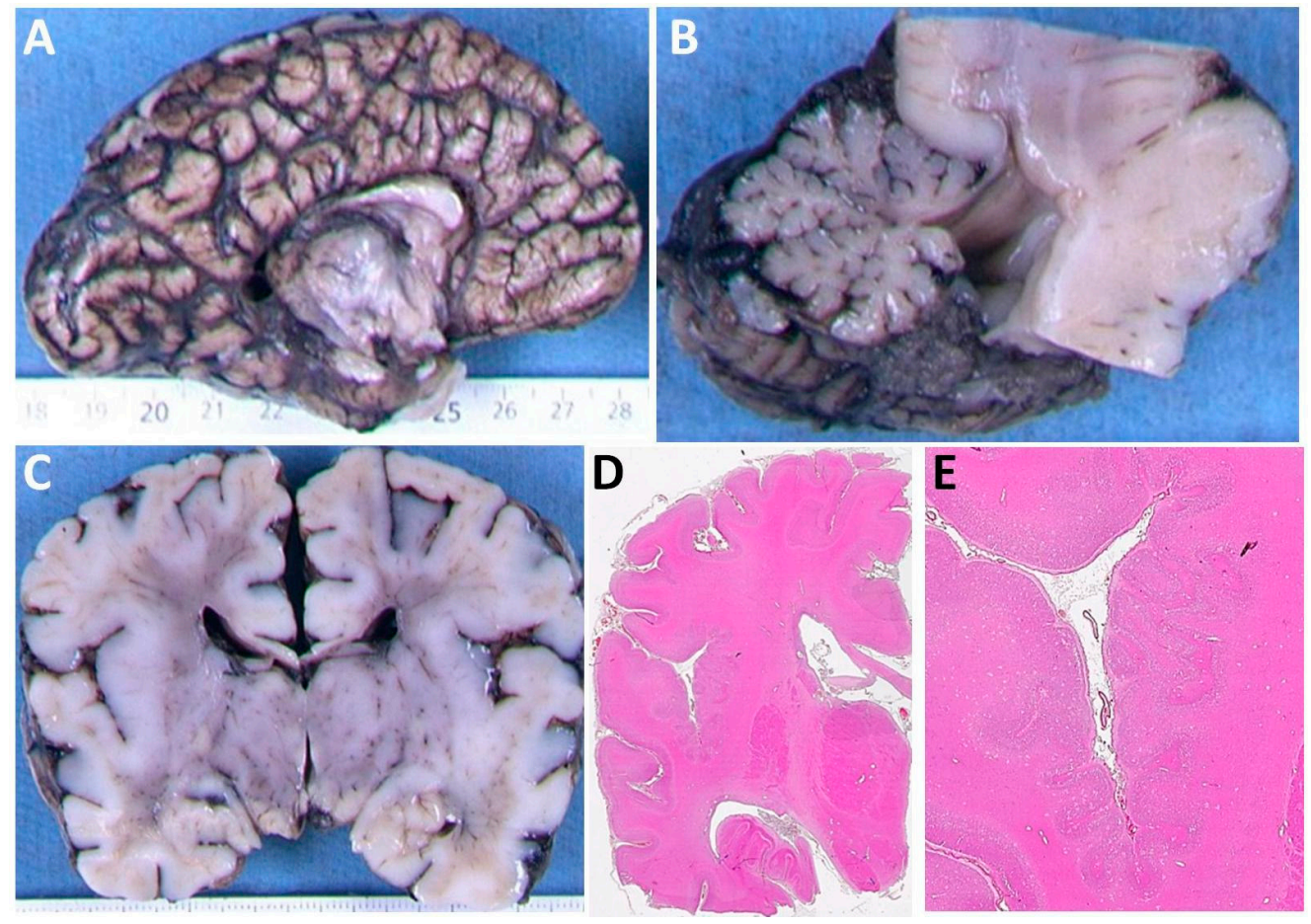

Figure 2. Neuropathology from Patient 4. (A) The medial aspect of right cerebral hemisphere showing a thin corpus callosom with absent rostrum. (B) Midline sagittal section of brain stem and cerebellum showing mild hypoplasia of the cerebellar vermis. (C) Coronal section of the cerebral hemispheres. The corpus callosum is thinned and there is thickening of the cortex around the sylvian fissures. (D) Stained section of the right cerebral hemisphere revealing abnormal folding of the cortical ribbon around the sylvian fissure. (E) A magnified view of (D) demonstrating polymicrogyria around the sylvian fissure.

\subsection{Modelling the Structural Effects of p.Arg2His}

The Arg2 residue of TUBA1A is highly conserved across species and tubulin isoforms (Figure S1). The p.(Arg2His) variant is not present in gnomAD and multiple in silico prediction tools suggest it is deleterious (Table S1). However, the physicochemical difference between arginine and histidine is relatively small (Grantham difference 29) with both of the residues having positively-charged side chains. The c.5G $>$ A change is predicted to have minimal effects on the splicing at the adjacent splice acceptor site (Figure S2). When incorporated into polymerised microtubule, the $\mathrm{N}$-terminus of alpha-tubulin is positioned near the inter-dimer interface, between the alpha-tubulin subunit of one heterodimer and the beta subunit of the next heterodimer. To study the effects of p.Arg2His on the three-dimensional structure of the protein, we compared wild-type and mutant TUBA1A by modelling the alpha/beta-tubulin heterodimer (Figure 3A,B) (the protein variant is given here without brackets as we know the amino acid sequence in a simulation). The effects of the mutation were mild. No predicted hydrogen bonding was lost or gained between the alpha- and beta-tubulin subunits as a result of p.Arg2His. A hydrogen bond between Arg2 and the highly-conserved Cys4 residue within TUBA1A was lost. In addition, new bonds between Glu3, and both Asn50 and Thr130 were predicted to form as a result of the substitution. Additional conformational changes were predicted to occur in a loop region (Asp38 to Asn51, Figure 3B), which may affect interactions between heterodimers. 


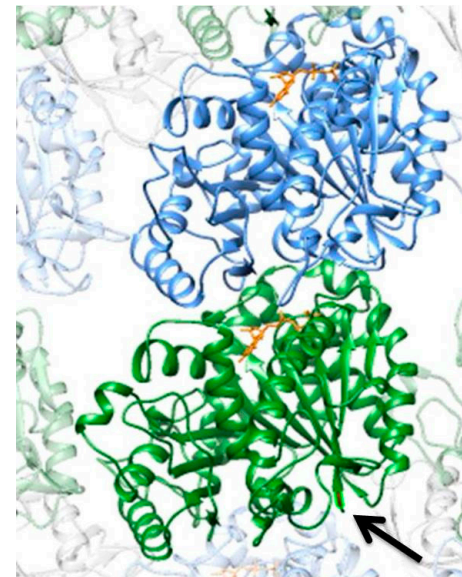

A

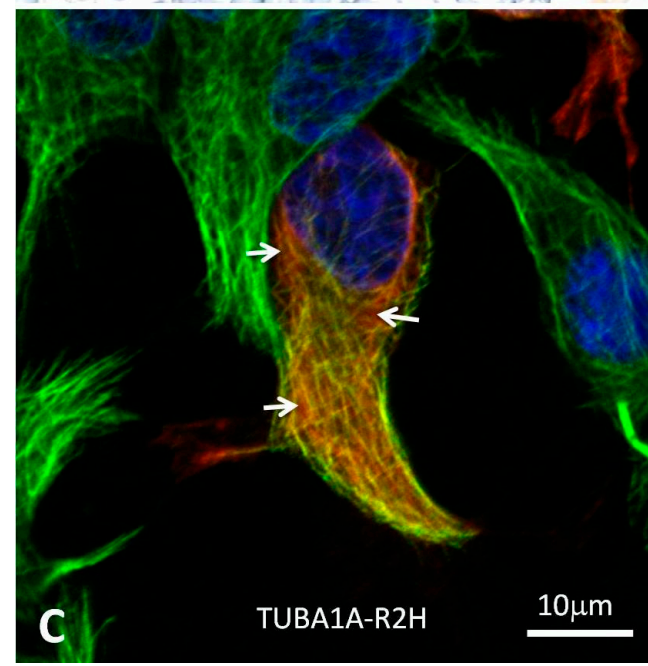

B
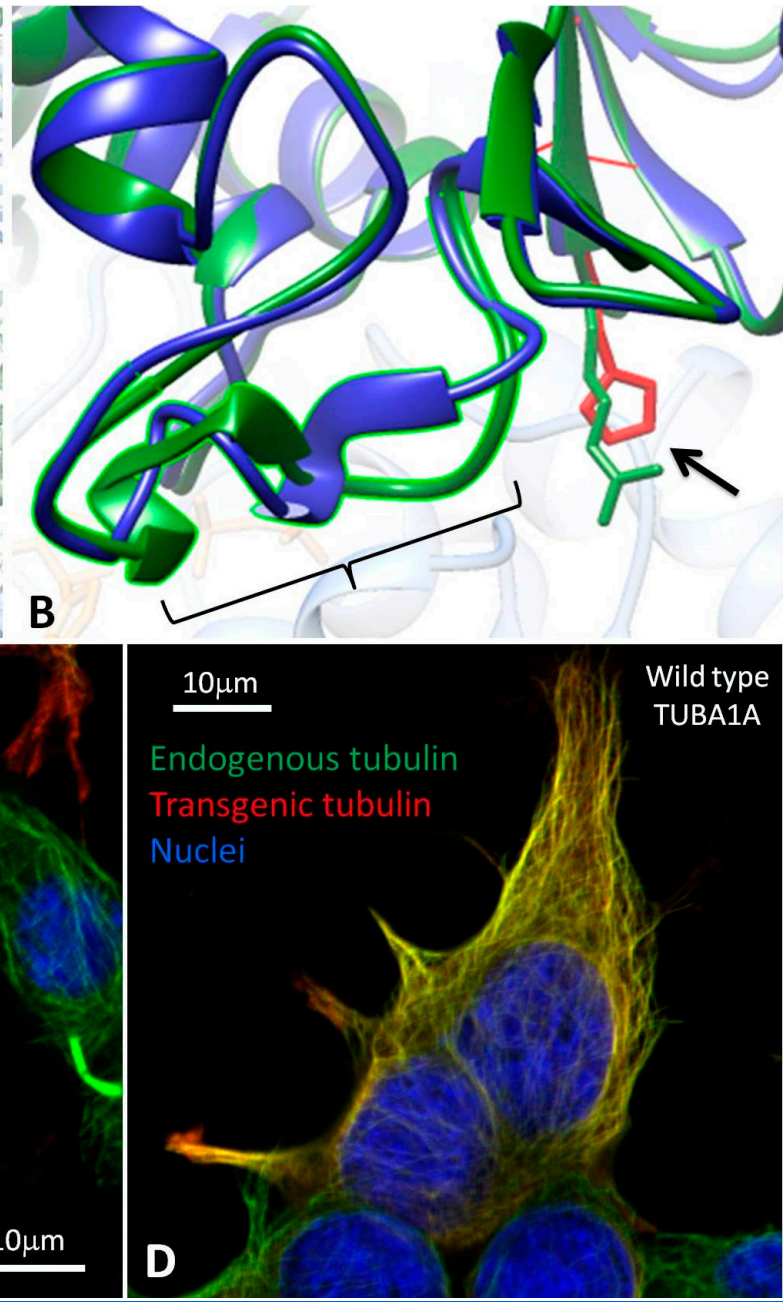

Figure 3. In silico modelling and in vitro functional analysis of the p.(Arg2His) mutation. (A) Ribbon models of alpha-tubulin (green) and beta-tubulin (blue) subunits aligned in a microtubule polymer. The position of Arg2 is shown (arrow) close to the inter-dimer interface (between alpha-tubulin and the beta-tubulin of an adjacent heterodimer). The mutation is on the opposite side of TUBA1A from the binding site of guanosine-5'-triphosphate (GTP, orange). (B) A close-up view of the Arg2 residue (arrow) with the mutant (purple ribbon, red side chain) and wild type (green ribbon and side chain) proteins superimposed. Only mild confirmation changes are predicted around the Arg2 residue. However, additional conformational changes are predicted between residues 38 and 51 (bracket). These may affect the interaction between heterodimers. (C) HEK-293 cells expressing FLAG-tagged TUBA1A-R2H. The cells are stained with DAPI (4',6-diamidino-2-phenylindole, blue), anti-FLAG- (red), and anti-alpha-tubulin (green) antibodies. The microtubules appear yellow due to the colocalisation of endogenous (green) and FLAG-tagged transgenic (red) tubulin. The arrows indicate diffuse patches of transgenic mutant tubulin (red) in the cytoplasm between the microtubules. (D) Control cells expressing FLAG-tagged wild-type TUBA1A have less staining for the transgenic tubulin in the cytoplasm between the microtubules.

\subsection{Heterologous Expression of TUBA1A-R2H in HEK-293 cells}

TUBA1A containing the p.(Arg2His) mutation (TUBA1A-R2H) was expressed in cultured HEK-293 cells. TUBA1A-R2H incorporated into the microtubule polymer network (Figure 3C), suggesting that it successfully folds and dimerises with endogenous beta-tubulin. However, in comparison to wild-type TUBA1A (Figure 3D), there was a slight increase in the proportion of the mutant FLAG-tagged protein seen unpolymerised within the cytosol. This suggests the mutation subtly alters the function 
(folding, dimerisation, or coassembly) of the subunit, but that once incorporated the dynamics of the mutant subunit are similar to wild type.

\subsection{Substitution Probability of Recurrent TUBA1A Mutations}

The observation of p.(Arg2His) on four separate occasions suggested that it was a common recurrent TUBA1A mutation. However, we noted that p.(Arg2His) had not been reported in previous large tubulinopathy cohorts [6]. In contrast, several TUBA1A mutations have been found recurrently in tubulinopathy patients. Examples include p.(Arg214His) [6,36], p.(Arg264Cys) [3,18,19], p.(Arg390Cys) [17,37], p.(Arg402His) [3,17,38,39], p.(Arg402Cys) [17,19], and p.(Arg422His) [17,18,40]. This made us wonder whether p.(Arg2His) had a lower mutation rate than the other recurrent TUBA1A mutations or whether it was just ascertained less frequently. We observed that the recurrent mutations all occurred at $\mathrm{CpG}$ sites, which are prone to spontaneous deamination (CGx is the codon for arginine). This highlighted that sequence context was likely to be an important factor. To predict the substitution rates at these sites and to compare them with the rest of TUBA1A, we estimated the probability of all possible single-base substitutions in TUBA1A based on heptanucleotide context (target position and three flanking nucleotides either side). Heptanucleotide context has been shown to explain $>81 \%$ of variability in substitution probabilities [33]. We found the seven recurrent TUBA1A mutations all ranked in the top $1 \%$ for substitution probability. The p.(Arg2His) mutation was the second highest in the group (ranking 7th out of 4548 possible substitutions) (Table S2). These results suggest p.(Arg2His) has a mutation rate that is similar to other recurrent TUBA1A mutations. The lack of observations in previous tubulinopathy cohorts may therefore reflect differences in ascertainment.

\section{Discussion}

In this report, we describe four patients with the TUBA1A p.(Arg2His) mutation. The patients had similar phenotypes with mild variability. Shared features included developmental delay, microcephaly, hypoplasia, and dysplasia of the cerebellar vermis, dysplasia or thinning of the corpus callosum, and dysmorphic basal ganglia. The pons tended to be small, disproportionally affecting the belly of the pons. We suspect the pons is dyspastic (i.e., abnormally developed) as well as small. Histopathological abnormalities of the pons were noted in patient 4. Two of the patients had bilateral perisylvian polymicrogyria. These features are typical of a tubulinopathy spectrum disorder [6]. Our findings suggest that p.(Arg2His) is a common recurrent TUBA1A mutation. Tubulinopathy patients are often ascertained due to cortical malformations (e.g., the classical lissencephaly associated with the recurrent p.(Arg402His) mutation)). In contrast, p.(Arg2His) does not cause an extensive cortical malformation. This may explain why p.(Arg2His) has not been observed in previous tubulinopathy cohorts [6].

Phenotypic variability that is associated with recurrent TUBA1A mutations has previously been noted. For example, the p.(Arg390Cys) mutation was first reported in a patient with mild gyral simplification, complete agenesis of the corpus callosum, and cerebellar hypoplasia [17]. It was subsequently reported in a patient with asymmetrical perisylvian polymicrogyria, hypoplasia of the corpus callosum, dysplastic cerebellar vermis, dysmorphic basal ganglia, and severe hypoplasia of brainstem [37]. Similarly, p.(Arg214His) was initially reported in a fetus with central polymicrogyria-like cortical dysplasia, complete agenesis of the corpus callosum, and normal cerebellum [6]. It was then reported in a patient with diffuse irregular gyration and sulcation of the cortex, partial agenesis of the corpus callosum, hypoplasia of the cerebellar vermis, and globular thalami [36]. As with p.(Arg2His), these descriptions suggest variability, but with overlap in key elements of the phenotype (abnormalities of the cortex, corpus callosum, cerebellum, and basal ganglia). Some of the variability may be due to differences in the interpretation of the brain imaging. However, differences in genetic background, environmental factors, or random chance may also contribute. Oegema et al. [36] found that p.(Arg214His) caused only a mild functional deficit (incorporating into microtubule polymers at comparable levels to wild type but at a reduced rate) and subtle 
predicted structural effects. Mutations with relatively mild functional effects (such as p.(Arg214His) or p.(Arg2His)) may allow for other factors to influence phenotype outcome.

Mutations of the homologous Arg2 residue in other tubulin isoforms have been linked to human disease phenotypes. TUBB8 is the main beta-tubulin of oocytes. The p.(Arg2Lys) mutation in TUBB8 has been found to cause arrest of oocyte meosis [41]. The mutation is thought to affect folding of the protein as well as the assembly and stability of heterodimers. The p.(Arg2Met) mutation in TUBB8 has also been shown to cause arrest of oocyte maturation [42,43]. TUBB4A is a brain-expressed beta-tubulin isoform. A p.(Arg2Gly) mutation in TUBB4A has been identified in a family with dystonia type 4 ('Whispering dysphonia') [44,45]. TUBB4A p.(Arg2Trp) and p.(Arg2Gln) have been reported to cause hypomyelination with atrophy of the basal ganglia and cerebellum [46,47]. The Arg2 of TUBB4A is part of the MREI (Met-Arg-Glu-Ile) 'auto-regulatory' domain, which is involved in controlling the amount of the beta-tubulin produced by the cell. In addition, these mutations disrupt a salt bridge Arg2 forms with Asp249 in TUBB4A [48]. This salt bridge is not predicted to occur in TUBA1A as the homologous residues are further apart.

\section{Conclusions}

We have shown that the TUBA1A c.5G>A, p.(Arg2His) mutation causes cortical, callosal, and cerebellar abnormalities that are typical of tubulinopathy-associated brain malformations. Based on its sequence context (and observation in four unrelated patients), c.5G $>\mathrm{A}$ is likely to be a common recurrent mutation in TUBA1A. Our functional and computer modelling results suggest that p.(Arg2His) has subtle effects on microtubule function, possibly acting at the inter-dimer interface. We propose that the subtle functional effects of the mutation may allow for other factors (e.g., genetic background, environmental conditions, or random chance) to modulate outcome, explaining the mild phenotypic variability observed.

Supplementary Materials: The following are available online at http:/ /www.mdpi.com/2076-3425/8/8/145/s1, Supplementary File 1 containing Figure S1: Sequences from orthologs and paralogs of TUBA1A demonstrating conservation of the Arg2 residue, Figure S2: In silico RNA splicing prediction reports, Table S1: In silico predictions and population data, and the detailed clinical descriptions of the four patients with the TUBA1A p.(Arg2His) mutation; Supplementary File 2 containing Table S2: The substitution probabilities for 4548 possible substitutions in the TUBA1A gene based on heptanucleotide sequence context.

Author Contributions: Conceptualization, T.D.C. and A.E.F.; Formal analysis, T.D.C. and A.E.F.; Investigation, J.F.G., T.D.C., G.N., H.E.O., P.E.G., R.H.S., N.S., J.S.C., S.N., T.A.-B., M.B., L.B., F.E.-R., S.M.P.-S., H.M., D.T.P. and A.E.F.; Software, T.D.C., J.G.L.M. and A.E.F.; Writing-original draft, J.F.G., T.D.C. and A.E.F.; Writing-review \& editing, G.N., H.E.O., P.E.G., R.H.S., N.S., J.S.C., S.N., T.A.-B., M.B., L.B., F.E-R., S.M.P.-S., H.M., J.G.L.M. and D.T.P.

Funding: The project was supported by the Wales Gene Park and the Wales Epilepsy Research Network.

Acknowledgments: The authors would like to thank the patients, families, clinicians and scientists who contributed to this work. We would like to thank Mark I. Rees (College of Medicine, Swansea University) for donating the wild-type pRK5-TUBA1A-C-FLAG construct.

Conflicts of Interest: The authors declare no conflict of interest.

\section{References}

1. Gloster, A.; Wu, W.; Speelman, A.; Weiss, S.; Causing, C.; Pozniak, C.; Reynolds, B.; Chang, E.; Toma, J.G.; Miller, F.D. The $\mathrm{T}$ alpha 1 alpha-tubulin promoter specifies gene expression as a function of neuronal growth and regeneration in transgenic mice. J. Neurosci. 1994, 14, 7319-7330. [CrossRef] [PubMed]

2. Bamji, S.X.; Miller, F.D. Comparison of the expression of a $\mathrm{T}$ alpha 1:nlacZ transgene and $\mathrm{T}$ alpha 1 alpha-tubulin mRNA in the mature central nervous system. J. Comp. Neurol. 1996, 374, 52-69. [CrossRef]

3. Keays, D.A.; Tian, G.; Poirier, K.; Huang, G.-J.; Siebold, C.; Cleak, J.; Oliver, P.L.; Fray, M.; Harvey, R.J.; Molnár, Z.; et al. Mutations in alpha-tubulin cause abnormal neuronal migration in mice and lissencephaly in humans. Cell 2007, 128, 45-57. [CrossRef] [PubMed] 
4. Jansen, A.C.; Oostra, A.; Desprechins, B.; De Vlaeminck, Y.; Verhelst, H.; Régal, L.; Verloo, P.; Bockaert, N.; Keymolen, K.; Seneca, S.; et al. TUBA1A mutations: from isolated lissencephaly to familial polymicrogyria. Neurology 2011, 76, 988-992. [CrossRef] [PubMed]

5. Cushion, T.D.; Dobyns, W.B.; Mullins, J.G.L.; Stoodley, N.; Chung, S.-K.; Fry, A.E.; Hehr, U.; Gunny, R.; Aylsworth, A.S.; Prabhakar, P.; et al. Overlapping cortical malformations and mutations in TUBB2B and TUBA1A. Brain 2013, 136, 536-548. [CrossRef] [PubMed]

6. Bahi-Buisson, N.; Poirier, K.; Fourniol, F.; Saillour, Y.; Valence, S.; Lebrun, N.; Hully, M.; Bianco, C.F.; Boddaert, N.; Elie, C.; et al. The wide spectrum of tubulinopathies: what are the key features for the diagnosis? Brain 2014, 137, 1676-1700. [CrossRef] [PubMed]

7. Sanders, S.J.; Murtha, M.T.; Gupta, A.R.; Murdoch, J.D.; Raubeson, M.J.; Willsey, A.J.; Ercan-Sencicek, A.G.; DiLullo, N.M.; Parikshak, N.N.; Stein, J.L.; et al. De novo mutations revealed by whole-exome sequencing are strongly associated with autism. Nature 2012, 485, 237-241. [CrossRef] [PubMed]

8. McMichael, G.; Girirajan, S.; Moreno-De-Luca, A.; Gecz, J.; Shard, C.; Nguyen, L.S.; Nicholl, J.; Gibson, C.; Haan, E.; Eichler, E.; et al. Rare copy number variation in cerebral palsy. Eur. J. Hum. Genet. 2014, 22, 40-45. [CrossRef] [PubMed]

9. Yokoi, S.; Ishihara, N.; Miya, F.; Tsutsumi, M.; Yanagihara, I.; Fujita, N.; Yamamoto, H.; Kato, M.; Okamoto, N.; Tsunoda, T.; et al. TUBA1A mutation can cause a hydranencephaly-like severe form of cortical dysgenesis. Sci. Rep. 2015, 5, 15165. [CrossRef] [PubMed]

10. Jaglin, X.H.; Poirier, K.; Saillour, Y.; Buhler, E.; Tian, G.; Bahi-Buisson, N.; Fallet-Bianco, C.; Phan-Dinh-Tuy, F.; Kong, X.P.; Bomont, P.; et al. Mutations in the beta-tubulin gene TUBB2B result in asymmetrical polymicrogyria. Nat. Genet. 2009, 41, 746-752. [CrossRef] [PubMed]

11. Tischfield, M.A.; Baris, H.N.; Wu, C.; Rudolph, G.; Van Maldergem, L.; He, W.; Chan, W.-M.; Andrews, C.; Demer, J.L.; Robertson, R.L.; et al. Human TUBB3 mutations perturb microtubule dynamics, kinesin interactions, and axon guidance. Cell 2010, 140, 74-87. [CrossRef] [PubMed]

12. Poirier, K.; Saillour, Y.; Bahi-Buisson, N.; Jaglin, X.H.; Fallet-Bianco, C.; Nabbout, R.; Castelnau-Ptakhine, L.; Roubertie, A.; Attie-Bitach, T.; Desguerre, I.; et al. Mutations in the neuronal $\beta$-tubulin subunit TUBB3 result in malformation of cortical development and neuronal migration defects. Hum. Mol. Genet. 2010, 19, 4462-4473. [CrossRef] [PubMed]

13. Breuss, M.; Heng, J.I.-T.; Poirier, K.; Tian, G.; Jaglin, X.H.; Qu, Z.; Braun, A.; Gstrein, T.; Ngo, L.; Haas, M.; et al. Mutations in the $\beta$-tubulin gene TUBB5 cause microcephaly with structural brain abnormalities. Cell Rep. 2012, 2, 1554-1562. [CrossRef] [PubMed]

14. Cushion, T.D.; Paciorkowski, A.R.; Pilz, D.T.; Mullins, J.G.L.; Seltzer, L.E.; Marion, R.W.; Tuttle, E.; Ghoneim, D.; Christian, S.L.; Chung, S.-K.; et al. De novo mutations in the beta-tubulin gene TUBB2A cause simplified gyral patterning and infantile-onset epilepsy. Am. J. Hum. Genet. 2014, 94, 634-641. [CrossRef] [PubMed]

15. Poirier, K.; Lebrun, N.; Broix, L.; Tian, G.; Saillour, Y.; Boscheron, C.; Parrini, E.; Valence, S.; Pierre, B.S.; Oger, M.; et al. Mutations in TUBG1, DYNC1H1, KIF5C and KIF2A cause malformations of cortical development and microcephaly. Nat. Genet. 2013, 45, 639-647. [CrossRef] [PubMed]

16. Romaniello, R.; Arrigoni, F.; Panzeri, E.; Poretti, A.; Micalizzi, A.; Citterio, A.; Bedeschi, M.F.; Berardinelli, A.; Cusmai, R.; D'Arrigo, S.; et al. Tubulin-related cerebellar dysplasia: definition of a distinct pattern of cerebellar malformation. Eur. Radiol. 2017, 27, 5080-5092. [CrossRef] [PubMed]

17. Kumar, R.A.; Pilz, D.T.; Babatz, T.D.; Cushion, T.D.; Harvey, K.; Topf, M.; Yates, L.; Robb, S.; Uyanik, G.; Mancini, G.M.S.; et al. TUBA1A mutations cause wide spectrum lissencephaly (smooth brain) and suggest that multiple neuronal migration pathways converge on alpha tubulins. Hum. Mol. Genet. 2010, 19, 2817-2827. [CrossRef] [PubMed]

18. Bahi-Buisson, N.; Poirier, K.; Boddaert, N.; Saillour, Y.; Castelnau, L.; Philip, N.; Buyse, G.; Villard, L.; Joriot, S.; Marret, S.; et al. Refinement of cortical dysgeneses spectrum associated with TUBA1A mutations. J. Med. Genet. 2008, 45, 647-653. [CrossRef] [PubMed]

19. Poirier, K.; Keays, D.A.; Francis, F.; Saillour, Y.; Bahi, N.; Manouvrier, S.; Fallet-Bianco, C.; Pasquier, L.; Toutain, A.; Tuy, F.P.D.; et al. Large spectrum of lissencephaly and pachygyria phenotypes resulting from de novo missense mutations in tubulin alpha 1A (TUBA1A). Hum. Mutat. 2007, 28, 1055-1064. [CrossRef] [PubMed] 
20. Tian, G.; Kong, X.-P.; Jaglin, X.H.; Chelly, J.; Keays, D.; Cowan, N.J. A pachygyria-causing alpha-tubulin mutation results in inefficient cycling with CCT and a deficient interaction with TBCB. Mol. Biol. Cell 2008, 19, 1152-1161. [CrossRef] [PubMed]

21. Farwell, K.D.; Shahmirzadi, L.; El-Khechen, D.; Powis, Z.; Chao, E.C.; Tippin Davis, B.; Baxter, R.M.; Zeng, W.; Mroske, C.; Parra, M.C.; et al. Enhanced utility of family-centered diagnostic exome sequencing with inheritance model-based analysis: results from 500 unselected families with undiagnosed genetic conditions. Genet. Med. 2015, 17, 578-586. [CrossRef] [PubMed]

22. Alby, C.; Malan, V.; Boutaud, L.; Marangoni, M.A.; Bessières, B.; Bonniere, M.; Ichkou, A.; Elkhartoufi, N.; Bahi-Buisson, N.; Sonigo, P.; et al. Clinical, genetic and neuropathological findings in a series of 138 fetuses with a corpus callosum malformation. Birth Defects Res. Part A Clin. Mol. Teratol. 2016, 106, 36-46. [CrossRef] [PubMed]

23. Srivastava, S.; Cohen, J.S.; Vernon, H.; Barañano, K.; McClellan, R.; Jamal, L.; Naidu, S.; Fatemi, A. Clinical whole exome sequencing in child neurology practice. Ann. Neurol. 2014, 76, 473-483. [CrossRef] [PubMed]

24. Alby, C.; Boutaud, L.; Bessières, B.; Serre, V.; Rio, M.; Cormier-Daire, V.; de Oliveira, J.; Ichkou, A.; Mouthon, L.; Gordon, C.T.; et al. Novel de novo ZBTB20 mutations in three cases with Primrose syndrome and constant corpus callosum anomalies. Am. J. Med. Genet. A 2018, 176, 1091-1098. [CrossRef] [PubMed]

25. Alby, C.; Boutaud, L.; Bonnière, M.; Collardeau-Frachon, S.; Guibaud, L.; Lopez, E.; Bruel, A.-L.; Aral, B.; Sonigo, P.; Roth, P.; et al. In utero ultrasound diagnosis of corpus callosum agenesis leading to the identification of orofaciodigital type 1 syndrome in female fetuses. Birth Defects Res. 2018, 110, 382-389. [CrossRef] [PubMed]

26. Mullins, J.G.L. Structural modelling pipelines in next generation sequencing projects. Adv. Protein Chem. Struct. Biol. 2012, 89, 117-167. [CrossRef] [PubMed]

27. Prota, A.E.; Bargsten, K.; Zurwerra, D.; Field, J.J.; Díaz, J.F.; Altmann, K.-H.; Steinmetz, M.O. Molecular mechanism of action of microtubule-stabilizing anticancer agents. Science 2013, 339, 587-590. [CrossRef] [PubMed]

28. Fourniol, F.J.; Sindelar, C.V.; Amigues, B.; Clare, D.K.; Thomas, G.; Perderiset, M.; Francis, F.; Houdusse, A.; Moores, C.A. Template-free 13-protofilament microtubule-MAP assembly visualized at 8 A resolution. J. Cell Biol. 2010, 191, 463-470. [CrossRef] [PubMed]

29. Webb, B.; Sali, A. Comparative Protein Structure Modeling Using MODELLER. Curr. Protoc. Bioinform. 2016, 54, 5.6.1-5.6.37. [CrossRef]

30. Pettersen, E.F.; Goddard, T.D.; Huang, C.C.; Couch, G.S.; Greenblatt, D.M.; Meng, E.C.; Ferrin, T.E. UCSF Chimera-A visualization system for exploratory research and analysis. J. Comput. Chem. 2004, 25, 1605-1612. [CrossRef] [PubMed]

31. UCSF Chimera Home Page. Available online: https://www.cgl.ucsf.edu/chimera/ (accessed on 23 July 2018).

32. Ensembl Genome Browser 93. Available online: http:/ / www.ensembl.org/index.html (accessed on 23 July 2018).

33. Aggarwala, V.; Voight, B.F. An expanded sequence context model broadly explains variability in polymorphism levels across the human genome. Nat. Genet. 2016, 48, 349-355. [CrossRef] [PubMed]

34. Wildeman, M.; van Ophuizen, E.; den Dunnen, J.T.; Taschner, P.E.M. Improving sequence variant descriptions in mutation databases and literature using the Mutalyzer sequence variation nomenclature checker. Hum. Mutat. 2008, 29, 6-13. [CrossRef] [PubMed]

35. Mutalyzer 2.0.28-Welcome to the Mutalyzer Website. Available online: https://www.mutalyzer.nl/ (accessed on 23 July 2018).

36. Oegema, R.; Cushion, T.D.; Phelps, I.G.; Chung, S.-K.; Dempsey, J.C.; Collins, S.; Mullins, J.G.L.; Dudding, T.; Gill, H.; Green, A.J.; et al. Recognizable cerebellar dysplasia associated with mutations in multiple tubulin genes. Hum. Mol. Genet. 2015, 24, 5313-5325. [CrossRef] [PubMed]

37. Poirier, K.; Saillour, Y.; Fourniol, F.; Francis, F.; Souville, I.; Valence, S.; Desguerre, I.; Marie Lepage, J.; Boddaert, N.; Line Jacquemont, M.; et al. Expanding the spectrum of TUBA1A-related cortical dysgenesis to Polymicrogyria. Eur. J. Hum. Genet. 2013, 21, 381-385. [CrossRef] [PubMed]

38. Kamiya, K.; Tanaka, F.; Ikeno, M.; Okumura, A.; Aoki, S. DTI tractography of lissencephaly caused by TUBA1A mutation. Neurol. Sci. 2014, 35, 801-803. [CrossRef] [PubMed]

39. Mokánszki, A.; Körhegyi, I.; Szabó, N.; Bereg, E.; Gergev, G.; Balogh, E.; Bessenyei, B.; Sümegi, A.; Morris-Rosendahl, D.J.; Sztriha, L.; et al. Lissencephaly and band heterotopia: LIS1, TUBA1A, and DCX mutations in Hungary. J. Child Neurol. 2012, 27, 1534-1540. [CrossRef] [PubMed] 
40. Morris-Rosendahl, D.J.; Najm, J.; Lachmeijer, A.M.A.; Sztriha, L.; Martins, M.; Kuechler, A.; Haug, V.; Zeschnigk, C.; Martin, P.; Santos, M.; et al. Refining the phenotype of alpha-1a Tubulin (TUBA1A) mutation in patients with classical lissencephaly. Clin. Genet. 2008, 74, 425-433. [CrossRef] [PubMed]

41. Feng, R.; Sang, Q.; Kuang, Y.; Sun, X.; Yan, Z.; Zhang, S.; Shi, J.; Tian, G.; Luchniak, A.; Fukuda, Y.; et al. Mutations in TUBB8 and Human Oocyte Meiotic Arrest. N. Engl. J. Med. 2016, 374, 223-232. [CrossRef] [PubMed]

42. Chen, B.; Li, B.; Li, D.; Yan, Z.; Mao, X.; Xu, Y.; Mu, J.; Li, Q.; Jin, L.; He, L.; et al. Novel mutations and structural deletions in TUBB8: Expanding mutational and phenotypic spectrum of patients with arrest in oocyte maturation, fertilization or early embryonic development. Hum. Reprod. 2017, 32, 457-464. [CrossRef] [PubMed]

43. Huang, L.; Tong, X.; Luo, L.; Zheng, S.; Jin, R.; Fu, Y.; Zhou, G.; Li, D.; Liu, Y. Mutation analysis of the TUBB8 gene in nine infertile women with oocyte maturation arrest. Reprod. Biomed. Online 2017, 35, 305-310. [CrossRef] [PubMed]

44. Lohmann, K.; Wilcox, R.A.; Winkler, S.; Ramirez, A.; Rakovic, A.; Park, J.-S.; Arns, B.; Lohnau, T.; Groen, J.; Kasten, M.; et al. Whispering dysphonia (DYT4 dystonia) is caused by a mutation in the TUBB4 gene. Ann. Neurol. 2013, 73, 537-545. [CrossRef] [PubMed]

45. Hersheson, J.; Mencacci, N.E.; Davis, M.; MacDonald, N.; Trabzuni, D.; Ryten, M.; Pittman, A.; Paudel, R.; Kara, E.; Fawcett, K.; et al. Mutations in the autoregulatory domain of $\beta$-tubulin 4 a cause hereditary dystonia. Ann. Neurol. 2013, 73, 546-553. [CrossRef] [PubMed]

46. Hamilton, E.M.; Polder, E.; Vanderver, A.; Naidu, S.; Schiffmann, R.; Fisher, K.; Raguž, A.B.; Blumkin, L.; H-ABC Research Group; van Berkel, C.G.M.; et al. Hypomyelination with atrophy of the basal ganglia and cerebellum: further delineation of the phenotype and genotype-phenotype correlation. Brain 2014, 137, 1921-1930. [CrossRef] [PubMed]

47. Miyatake, S.; Osaka, H.; Shiina, M.; Sasaki, M.; Takanashi, J.-I.; Haginoya, K.; Wada, T.; Morimoto, M.; Ando, N.; Ikuta, Y.; et al. Expanding the phenotypic spectrum of TUBB4A-associated hypomyelinating leukoencephalopathies. Neurology 2014, 82, 2230-2237. [CrossRef] [PubMed]

48. Simons, C.; Wolf, N.I.; McNeil, N.; Caldovic, L.; Devaney, J.M.; Takanohashi, A.; Crawford, J.; Ru, K.; Grimmond, S.M.; Miller, D.; et al. A de novo mutation in the $\beta$-tubulin gene TUBB4A results in the leukoencephalopathy hypomyelination with atrophy of the basal ganglia and cerebellum. Am. J. Hum. Genet. 2013, 92, 767-773. [CrossRef] [PubMed] 